\title{
Development of Safe and Non-Self-Immunogenic Mucosal Adjuvant by Recombinant Fusion of Cholera Toxin A1 Subunit with Protein Transduction Domain
}

\author{
Byoung-Shik Shim $\mathbb{D}^{1},{ }^{1}$ In Su Cheon, ${ }^{1,2}$ Eugene Lee, ${ }^{1}$ Sung-Moo Park, ${ }^{1}$ Youngjoo Choi, \\ Dae-Im Jung, ${ }_{1}$ Eunji Yang, ${ }^{1}$ Jung-ah Choi, ${ }^{1}$ June Young Chun $(1),{ }^{1,3}$ Jae-Ouk Kim $\left(\mathbb{1},{ }^{1}\right.$ \\ Cheol-Heui Yun $\mathbb{B}^{2},{ }^{2}$ Cecil Czerkinsky, ${ }^{4}$ and Man Ki Song $\mathbb{( I D}^{1}$ \\ ${ }^{1}$ Laboratory Science Division, International Vaccine Institute, Seoul 08826, Republic of Korea \\ ${ }^{2}$ Department of Agricultural Biotechnology and Research Institute for Agriculture and Life Sciences, Seoul National University, \\ Seoul 08826, Republic of Korea \\ ${ }^{3}$ Department of Internal Medicine, Seoul National University College of Medicine, Seoul, Republic of Korea \\ ${ }^{4}$ Institut de Pharmacologie Moleculaire et Cellulaire, CNRS-INSERM-University of Nice-Sophia Antipolis, Valbonne, France
}

Correspondence should be addressed to Man Ki Song; mksong@ivi.int

Received 21 July 2017; Revised 3 December 2017; Accepted 10 December 2017; Published 7 March 2018

Academic Editor: Ethan M. Shevach

Copyright (c) 2018 Byoung-Shik Shim et al. This is an open access article distributed under the Creative Commons Attribution License, which permits unrestricted use, distribution, and reproduction in any medium, provided the original work is properly cited.

\begin{abstract}
Potential use of cholera toxin (CT) as a mucosal vaccine adjuvant has been documented in a variety of animal models. However, native CT is highly toxic to be used as a mucosal adjuvant in humans. Here, we demonstrate a new approach to generate a mucosal adjuvant by replacing the B subunit of CT with HIV-1 Tat protein transduction domain (PTD), which efficiently delivers fusion proteins into the cell cytoplasm by unspecific binding to cell surface. We compared the adjuvanticity and toxicity of Tat PTD-CTA1-Tat PTD (TCTA1T) with those of CT. Our results indicate that intranasal (i.n.) delivery of ovalbumin (OVA) with TCTA1T significantly augments the OVA-specific systemic and mucosal antibody responses to levels comparable to those seen with CT adjuvant. Moreover, in vivo cytotoxic T lymphocyte activity elicited by TCTA1T was significantly higher than that elicited by a mutant TCTA1T (TmCTA1T) lacking ADP-ribosyltransferase function. In addition, coadministration of influenza M2 protein with TCTA1T conferred near complete protection against lethal influenza virus challenge. Importantly, TCTA1T, in contrast to CT, did not induce serum IgG antibody responses to itself and was shown to be nontoxic. These results suggest that TCTA1T may be a safe and effective adjuvant when given by mucosal routes.
\end{abstract}

\section{Introduction}

Mucosal surfaces function as a barrier between the host interior and the external environment [1]. Since most pathogens invade the body through the mucosal epithelium [2], mucosal immunity serves a crucial role as the first line of defense against various infections [3]. A general consensus is that parenteral administration of vaccines generates a systemic immune response against the vaccine antigens (Ags), whereas mucosal vaccination can efficiently elicit both systemic and mucosal immune responses, including secretory $\operatorname{IgA}(\operatorname{sgA})$ antibodies which are strongly associated with mucosal host defense $[2,4]$. In addition, mucosal immunization possesses a number of advantages, including ease of administration and reduced risks of infection by contaminated injection devices. Nonetheless, only few mucosal vaccines have been licensed for human use and no mucosal adjuvant has yet been approved $[2,5]$. Despite their obvious advantages, the evident challenge faced by many candidate mucosal vaccines has been their inability to elicit adequate immune responses when administered via mucosal routes $[6,7]$. Such a challenge indicates that these candidate vaccines may require the use of 
proper adjuvant to efficiently generate immune responses that can offer protection against invading pathogens.

It is well known from animal studies that cholera toxin (CT) secreted by Vibrio cholerae and heat-labile enterotoxin (LT) from Escherichia coli (E. coli) retain potent mucosal adjuvanticity which helps to elicit both mucosal and systemic antibody $(\mathrm{Ab})$ responses against variety of Ags [8-12]. Both CT and LT are composed of enzymatically active A subunit which possesses ADP-ribosylating activity and pentameric B subunits which possesses monosialoganglioside (GM1) receptor-binding site. The A1 subunit (CTA1) of CT is internalized following binding of B subunits of CT to GM1 on the surface of intestinal epithelial cells [13]. Then, the internalized CTA1 induced ADP-ribosylation of the $\alpha$ subunit of the GTP binding regulatory protein Gs, resulting in the increased levels of cellular cyclic AMP (cAMP) which, in turn, cause secretion of chloride ions and water into the small intestine [14], the hallmark of cholera diarrhea in humans $[14,15]$. Because native CT and LT are not suitable as mucosal adjuvants in humans [16], a number of toxin-derived mutants, including LTR192G, LTK63, and CTA1-DD, have been engineered so as to retain adjuvanticity without toxicity $[1,3,17,18]$. Of these, LTR192G and LTK63 have already been evaluated in human clinical trials $[19,20]$.

It has been suggested that one of the important requirements for an ideal adjuvant is nonimmunogenicity to itself. This is due to potential development of the adjuvantspecific immunity capable of negating the immuneenhancing functionality of the adjuvant. Although adjuvant functionality of toxin-derived mutants, notably LTK63 and CTA1-DD, was not affected by preexisting antibodies to the adjuvants themselves $[21,22]$, a previous study reported that preexisting immunity to CTB can inhibit antibody responses to a coadministered $\mathrm{Ag}[23,24]$.

It has been known that protein delivery by so-called "protein transduction domain" (PTD) occurs in a rapid, concentration-dependent manner that appears to be independent of cell membrane receptors and cellular transporters $[25,26]$. Thereafter, PTD has been considered an ideal delivery vehicle that enables efficient transport of PTD-fusion proteins into living cells [26, 27]. Previous studies have shown that the PTD comprising nine amino acids (residues 49-57) from HIV-1 Tat protein is sufficient for the delivery of PTD-GFP fusion protein into cells [28] and that GFP fused with PTD at both termini displays increased translocation activity as compared to GFP fused with PTD at either N- or C-terminus alone [29].

In the above, considerations have prompted us to evaluate the adjuvant activity and potential toxicity of a novel mucosal adjuvant engineered by fusion of the HIV-1 Tat PTD to both termini of CTA1, which will be referred thereafter to as TCTA1T. In addition, we also examined whether TCTA1T is self-immunogenic, that is, can induce antibody responses to itself.

\section{Materials and Methods}

2.1. Construction of Plasmids Expressing TCTA1T and TmCTA1T Proteins. Plasmid (pET15b-Tat-GFP-Tat) expressing GFP protein with HIV-1 Tat PTD (amino acids 49-57) at both N-terminus and C-terminus was provided by Dr. Soo Young Choi at Hallym University, Korea. The gene corresponding to CTA1 subunit (amino acids 1194) was amplified with a forward primer $\left(5^{\prime}\right.$-GGGC CCCTCGAGAATGATGATAAGTTATATCGG-3' ${ }^{\prime}$ ) and a reverse primer $\left(5^{\prime}\right.$-CCCGGGGGATCCCGATGATCTTG GAGCATTCCC-3') by polymerase chain reaction (PCR). Vibrio cholerae N16961 strain (AE003852) was used as a template for CTA1 subunit. The PCR product was digested with Xho I and BamH I and then ligated to the pET15bTat-GFP-Tat plasmid which was linearized with the same enzymes, resulting in the recombinant plasmid pET15bTCTA1T. Plasmid pET15b-TmCTA1T, which has a point mutation (Ser63 $\rightarrow$ Lys) at ADP-ribosyltransferase enzymatic active site of CTA1, was generated by site-directed mutagenesis with $5^{\prime}$-TATGTTTCCACCAAGATTAGTTTG AGA-3' and $5^{\prime}$-TCTCAAACTAATCTTGGTGGAAACATA $-3^{\prime}$ primers using Pyrobest DNA polymerase (Takara, Japan). The pET15b-TCTA1T plasmid was used as a template for TmCTA1T (Figure 1(a)), and the DNA sequences were confirmed at Macrogen (Seoul, Korea).

\subsection{Expression and Purification of TCTA1T and TmCTA1T} Proteins. E. coli BL21 (DE3) strain (Novagen, Germany) was transformed with the pET15b-TCTA1T or pET15bTmCTA1T and was grown overnight at $37^{\circ} \mathrm{C}$ in LuriaBertani (LB) medium supplemented with $100 \mu \mathrm{g} / \mathrm{ml}$ of ampicillin. The overnight culture was transferred into fresh $\mathrm{LB}$ medium and cultured at $37^{\circ} \mathrm{C}$ while shaking at $180 \mathrm{rpm}$ until $\mathrm{OD}_{600}$ of $0.6 \sim 0.8$. Each protein expression was induced by addition of isopropyl $\beta$-D-thiogalactopyranoside (IPTG) to a final concentration at $0.5 \mathrm{M}$ for $4 \mathrm{hrs}$, and the cells were harvested by centrifugation at $6000 \mathrm{rpm}$ for $10 \mathrm{~min}$. The cell pellets were suspended in binding buffer $(20 \mathrm{mM}$ Tris, $0.5 \mathrm{M} \mathrm{NaCl}, 10 \%$ glycerol, $\mathrm{pH} 7.9$ ) and disrupted by sonication on ice. Then, the soluble and insoluble fractions were separated by centrifugation for $30 \mathrm{~min}$ at $18,000 \mathrm{rpm}$. The insoluble fraction was dissolved in binding buffer containing $6 \mathrm{M}$ urea. After centrifugation for $30 \mathrm{~min}$ at $18,000 \mathrm{rpm}$, the supernatant was applied to a Talon metal affinity column (Clontech, Palo Alto, CA). The column was washed with binding buffer, followed by wash buffer $(20 \mathrm{mM}$ Tris, $0.5 \mathrm{M}$ $\mathrm{NaCl}$, and $20 \mathrm{mM}$ imidazole, $\mathrm{pH} 7.9$ ) without urea. Then, the proteins were eluted with elution buffer $(20 \mathrm{mM}$ Tris, $0.5 \mathrm{M} \mathrm{NaCl}, 0.3 \mathrm{M}$ imidazole, $10 \%$ glycerol, $\mathrm{pH} 7.9)$. The purified proteins were electrophoresed on 12.5\% SDS-PAGE, and the protein bands were visualized by staining with Coomassie Brilliant Blue. The protein concentration was determined by Bradford protein assay kit (Bio-Rad, Richmond, CA). The purified proteins were aliquoted and stored at $-80^{\circ} \mathrm{C}$ until used.

2.3. Western Blot Analysis. The purified proteins were separated by $12.5 \%$ SDS-PAGE. After electrophoretic transfer to nitrocellulose membrane (Schleicher \& Schuell, Germany) by using a semidry transblot apparatus (Bio-Rad), the membrane was blocked with Tris-buffered saline (TBS) 
containing 5\% skim milk and incubated with goat anti-CT (Abcam, Cambridge, MA) at a $1: 1000$ dilution in TBST (TBS and $0.05 \%$ Tween 20 ) containing $5 \%$ skim milk. After washing with TBST, the membrane was probed with mouse-anti-goat IgG conjugated to horseradish peroxidase (Santa Cruz Biotechnology, Santa Cruz, CA) for $1 \mathrm{hr}$ and the band was visualized after the reaction with chromogenic substrate (ECL kit; Amersham Pharmacia Biotech Inc., Piscataway, NJ).

2.4. Transduction of TCTA1T into Cells. Analysis of the transduction of TCTA1T into cells was performed as previously described [28]. Briefly, HeLa cells were seeded at $5 \times 10^{5}$ cells/well in 6-well plates. $24 \mathrm{hrs}$ later, the cells were treated with $5 \mu \mathrm{g}$ CTA1 or 5 and $10 \mu \mathrm{g}$ TCTA1T and incubated in $\mathrm{CO}_{2}$ incubator for $2 \mathrm{hrs}$. The cells were washed with PBS three times and harvested by trypsinization. The cells were prepared for analysis by Western blot.

2.5. Immunization of Mice. Specific pathogen-free, female $\mathrm{BALB} / \mathrm{c}$ mice aged 6 weeks were purchased from Orient Bio Inc. (Korea). All mice were maintained under specific pathogen-free conditions, and all studies were approved by Institutional Animal Care and Use Committee (IACUC) of International Vaccine Institute (2010-018). Five mice per group were anesthetized with ketamine and immunized three times at a 2-week interval by i.n. injection of $20 \mu \mathrm{g}$ of ovalbumin (OVA; Sigma, St. Louis, MO) alone, or mixed with $10 \mu \mathrm{g}$ of TCTA1T and TmCTA1T, or $2 \mu \mathrm{g}$ of CT (List Biological Laboratories Inc., Campbell, CA). To examine adjuvant effect depending on the dose of TCTA1T, mice were immunized three times at a 2 -week interval by i.n. injection with $20 \mu \mathrm{g}$ of OVA alone, or mixed with $0.1,1.0,10$, or $20 \mu \mathrm{g}$ of TCTA1T. The treated mice were monitored daily and euthanized according to ethical guidelines of the IACUC as per the approved protocol.

2.6. Sample Collection. Sera and mucosal samples were collected on day 13 or 14 after the last immunization. Blood samples were collected from the retro-orbital plexus and centrifuged for $10 \mathrm{~min}$ at $13000 \mathrm{rpm}$, and sera were taken. Saliva samples were obtained after inducing salivary gland secretion by intraperitoneal (i.p.) injection of pilocarpine $(100 \mu \mathrm{l}$ of $1 \mathrm{mg} / \mathrm{ml}$; Sigma) diluted in sterile PBS. For Bronchoalveolar lavage (BAL) samples, the mice were dissected to expose the trachea. IV catheter (BD Biosciences, San Jose, CA) was inserted into a small nick of the trachea. BAL samples were collected by repeated flushing and aspiration with $500 \mu \mathrm{l}$ of PBS into the lungs. Nasal washes were collected by flushing with $50 \mu \mathrm{l}$ of PBS for two times through the nasal cavity. Lung tissues were cut in small pieces and subjected to freeze-thaw cycles twice. The tissues were centrifuged at $13000 \mathrm{rpm}$ at $4^{\circ} \mathrm{C}$ for $10 \mathrm{~min}$, and supernatant was collected to test for $\mathrm{Ag}$-specific $\mathrm{Ab}$ responses. The samples were stored at $-80^{\circ} \mathrm{C}$ until used.

2.7. Elisa. OVA-specific Ab titers were determined by ELISA. 96-well ELISA plates (Nunc, Roskilde, Denmark) were precoated with $100 \mu \mathrm{l}$ of OVA protein $(10 \mu \mathrm{g} / \mathrm{ml})$ in $50 \mathrm{mM}$ sodium bicarbonate buffer ( $\mathrm{pH} 9.6)$ overnight at $4^{\circ} \mathrm{C}$. After blocking with PBS containing 5\% skim milk for $1 \mathrm{hr}$ at room temperature, $100 \mu \mathrm{l}$ of 2- or 3-fold serially diluted samples in blocking buffer were added to each well and incubated for $1 \mathrm{hr}$ at $37^{\circ} \mathrm{C}$, followed by addition of $1: 3000$ diluted horseradish peroxidase-conjugated goat anti-mouse IgG, IgG1, IgG2a, or IgA (Santa Cruz biotechnology). After incubation for $1 \mathrm{hr}$ at room temperature, $100 \mu \mathrm{l}$ of peroxidase substrate tetramethylbenzidine (TMB) (Millipore, Bedford, MA) was added to each well. The reaction was stopped by addition of $0.5 \mathrm{~N} \mathrm{HCl}$. The absorbance at wavelength $450 \mathrm{~nm}$ was examined by using an ELISA reader (Molecular Devices, Sunnyvale, CA). The endpoint titer was determined by O.D. cutoff values of 0.2 .

2.8. In Vivo Cytotoxic T Lymphocyte Assay. Splenocytes from C57BL/6 mice were split into two equal fractions. One fraction was labeled with $5 \mu \mathrm{M}$ CFSE (Invitrogen) for $5 \mathrm{~min}$ at room temperature and pulsed with $1 \mu \mathrm{M} \mathrm{OVA}_{257-264}$ (SIINFEKL) peptide for $1 \mathrm{hr}$. The other fraction was labeled with $0.5 \mu \mathrm{M}$ CFSE without peptide pulse. Two fractions were mixed at a ratio of $1: 1$, and a total of $1.5 \times 10^{7}$ cells were injected intravenously (i.v.) into C57BL/6 mice, which were previously immunized three times at a 2 -week interval by i.n. injection with $100 \mu \mathrm{g}$ of OVA alone, or OVA plus $10 \mu \mathrm{g}$ of TCTA1T or TmCTA1T, or $2 \mu \mathrm{g}$ of CT. Single cells were prepared from the lung and spleen $24 \mathrm{hrs}$ after the cell transfer. Specific killing activity was measured by FACSCalibur ${ }^{\mathrm{TM}}$ (BD Biosciences, San Jose, CA).

2.9. Virus Challenge. BALB/c mice $(n=6)$ were immunized with $10 \mu \mathrm{g}$ of influenza $3 \mathrm{M} 2 \mathrm{eC}$ protein [30] with $10 \mu \mathrm{g}$ of TCTA1T and TmCTA1T or $2 \mu \mathrm{g}$ of CT as mucosal adjuvant by i.n. route on days 0 and 14 . Control mice were immunized with either PBS or TCTA1T alone. The mice were challenged i.n. with $10 \mathrm{LD}_{50}$ of $\mathrm{A} / \mathrm{PR} / 8$ virus three weeks after the last immunization. The mice were monitored daily for body weight loss and survival after the viral challenge.

2.10. Toxicity Test. To assess the footpad edema [31], mice were anesthetized with ketamine by i.p. injection and injected with $10 \mu \mathrm{g}$ of TCTA1T and TmCTA1T, or $1 \mu \mathrm{g}$ of CT in $10 \mu \mathrm{l}$ of PBS into the hind paw. The thickness of the footpad was measured after $24 \mathrm{hrs}$.

To perform the intestinal loop test [32], mice were deprived of food for overnight, but not of water. Next day, the mice were anesthetized, the abdomen was opened, and 3 to $5 \mathrm{~cm}$ loop was ligated in the middle part of the small intestine. $2 \mu \mathrm{g}$ of CT and $10 \mu \mathrm{g}$ of TCTA1T and TmCTA1T in $100 \mu \mathrm{l}$ of PBS were injected into the loops. PBS was used as a control. The abdomen was closed, the loop was weighed, and its length was determined $6 \mathrm{hrs}$ after the injection. Values were expressed as the weight per length ratio $(\mathrm{mg} / \mathrm{cm})$.

To test induction of cAMP accumulation, BHK21 cells (ATCC number CCL-10) were seeded at $1 \times 10^{6}$ cells/well in a 6-well plate. $24 \mathrm{hrs}$ later, the cells were washed with serum-free medium and incubated in the presence of $10 \mu \mathrm{g}$ of TCTA1T and TmCTA1T, or $1 \mu \mathrm{g}$ of CT for $3 \mathrm{hrs}$. Supernatant were obtained by centrifugation at $1000 \times \mathrm{g}$ for $10 \mathrm{~min}$. The concentration of cAMP in the supernatant was 


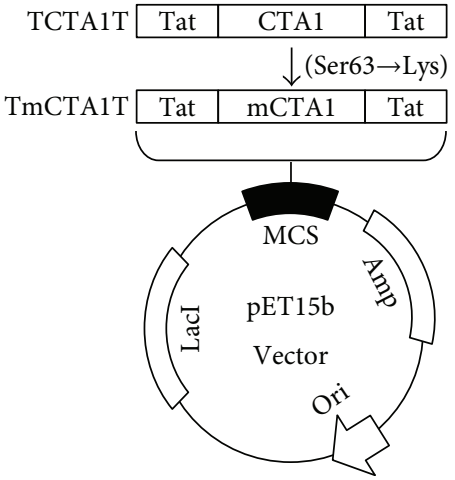

(a)

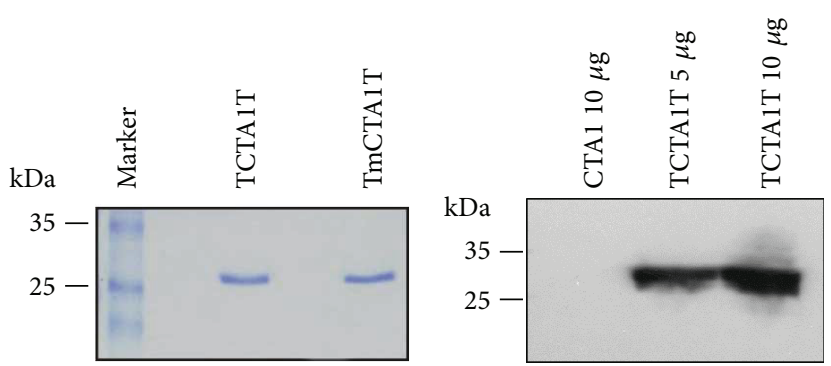

(b) (c)

FIGURE 1: Construction, purification, and transduction of the recombinant proteins. (a) Construction of plasmids expressing the proteins based on fusion of HIV-1 Tat PTD at termini of CTA1 or mCTA1. TmCTA1T was generated from TCTA1T by site-directed mutagenesis. (b) The fusion proteins expressed in E. coli were purified by His-tag affinity chromatography and separated by $12.5 \%$ SDS-PAGE. (c) The purified proteins were added to HeLa cells, and the presence of transduced proteins into the cells was detected by Western blot analysis.

measured by cyclic AMP EIA kit (Cayman, Michigan, MA) according to the manufacturer's instructions.

2.11. Toxicity Test of TCTA1T in Lung Tissue. To further assess toxicity of TCTA1T adjuvant in lung tissue [33], the mice were injected i.n. with 10 and $50 \mu \mathrm{g}$ of TCTA1T, or 1 , 5 , and $10 \mu \mathrm{g}$ of CT. PBS was used as control. The mice were monitored daily for the body weight loss following the injection. Lung tissues were weighed on day 4 after the injection.

2.12. Self-Immunogenic Response to TCTA1T. To evaluate self-immunogenicity of TCTA1T, BALB/c mice were immunized i.n. or intradermally (i.d.) for three times at 2 weeks apart with $10 \mu \mathrm{g}$ of TCTA1T or $2 \mu \mathrm{g}$ of CT. The sera were harvested at 2 weeks after the last immunization. The 96well ELISA plates were precoated with CTA1 $(1 \mu \mathrm{g} / \mathrm{ml})$ or CT $(2 \mu \mathrm{g} / \mathrm{ml})$ and CTA1- or CT-specific Ab titers were determined by ELISA as described above.

2.13. Statistical Analysis. Statistical tests were subjected to one-way analysis of variance (ANOVA) using SPSS software (SPSS Inc., Chicago, IL). A $P$ value of less than 0.05 was considered significant.

\section{Results}

3.1. Construction and Purification of Recombinant TCTA1T and TmCTA1T Proteins. A previous study has demonstrated that dual attachment of PTD onto both termini of GFP enhances the cellular uptake compared to the single PTD attachment at either terminus [29]. Accordingly, we constructed our candidate adjuvant TCTA1T by fusing HIV-1 Tat PTD onto both N-terminus and C-terminus of CTA1 subunit, which consequently allowed bypassing of CTBdependent cellular internalization of CTA1 (Figure 1(a)). Also, TmCTA1T, which has a point mutation (Ser63 $\rightarrow$ Lys) at ADP-ribosyltransferase enzymatic active site within CTA1 [34], was constructed from TCTA1T backbone via site-directed mutagenesis and used as negative control (Figure 1(a)). Both proteins were expressed in E. coli BL21 (DE3) strain and purified by His-tag affinity chromatography. The purified proteins were then analyzed by SDS-PAGE which displayed distinct bands at the expected molecular weight of $\sim 27 \mathrm{kDa}$ (Figure 1(b)). Further, the presence of proteins with correct size in the purified samples was confirmed by Western blot analysis performed using anti-CTAl Ab (data not shown).

3.2. Translocation of Recombinant TCTA1T Protein into Cells. To investigate whether TCTA1T possesses the capacity to translocate into target cells, HeLa cells were treated with 5 or $10 \mu \mathrm{g}$ TCTA1T or $5 \mu \mathrm{g}$ wild-type CTA1 (lacking HIV-1 Tat PTD fusion) for $2 \mathrm{hrs}$. Following incubation, cells were washed thoroughly with PBS to eliminate any residual TCTA1T or wild-type CTA1 from the growth media before being harvested and lysed. Cell lysates were analyzed for the presence of TCTA1T by Western blot. As expected, the presence of TCTA1T was detected in the lysates of cells treated with 5 or $10 \mu \mathrm{g}$ TCTA1T in a dose-dependent manner (Figure 1(c)). Whereas, the CTA1 without Tat PTD domain was not detected (Figure 1(c)). This result indicates that TCTA1T is able to permeate across the target cell membrane independently of the CTB domains which functions as a ligand for GM1 ganglioside receptor.

3.3. TCTA1T Enhances OVA-Specific Systemic and Mucosal $A b$ Responses. In order to examine the efficiency of TCTA1T in enhancing Ag-specific humoral immune response when used as a mucosal adjuvant, BALB/c mice were immunized three times i.n. with OVA alone, or OVA mixed with TCTA1T, TmCTA1T, or CT at 2-week intervals. Sera and mucosal secretions were collected from the immunized mice 13-14 days after the last immunization, and the levels of OVA-specific antibodies were measured. As shown in Figure 2(a), i.n. immunization with TCTA1T enhanced the OVA-specific serum IgG1 and IgG2a titers to levels that were comparable to those in mice immunized with CT. TmCTA1T lacking ADP-ribosyltransferase activity also enhanced the magnitude of OVA-specific serum IgG response compared to the control group that received OVA alone, but the levels of OVA-specific IgG1 and IgG2a titers 


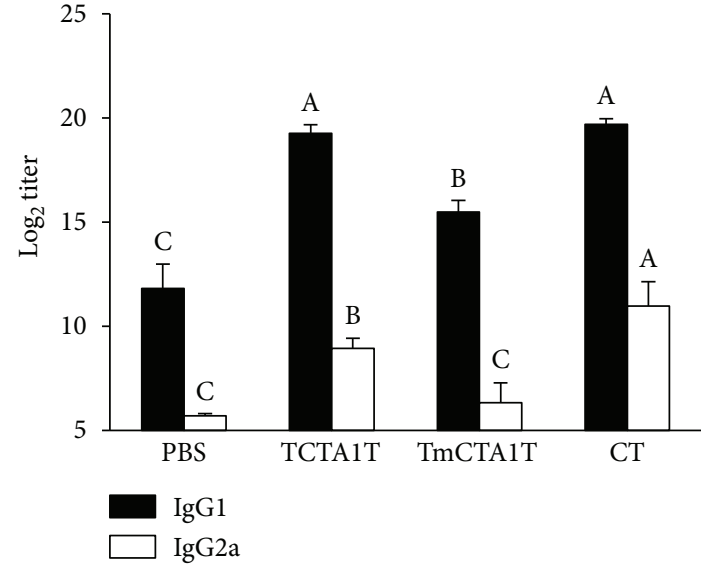

(a)

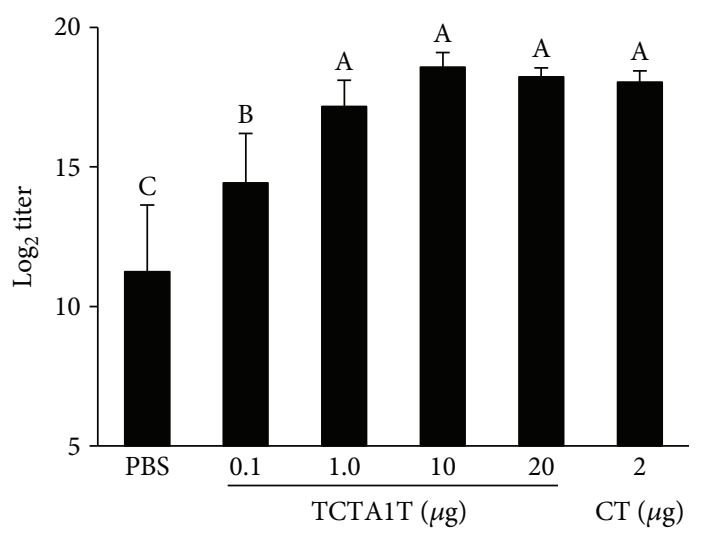

(c)

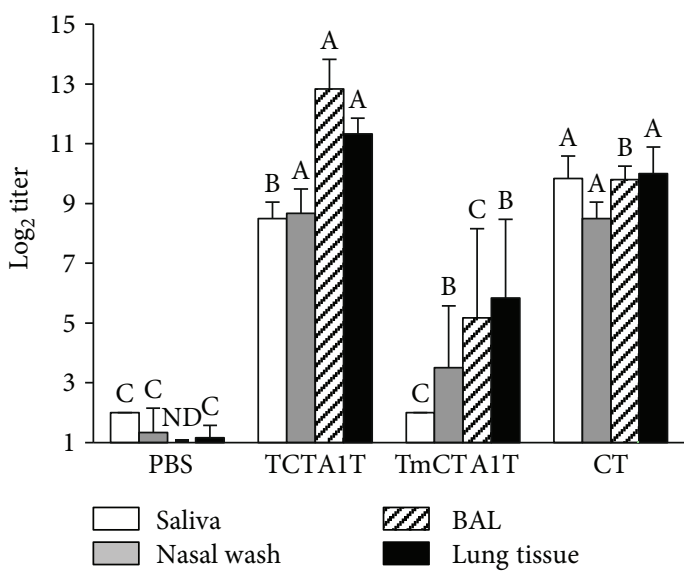

(b)

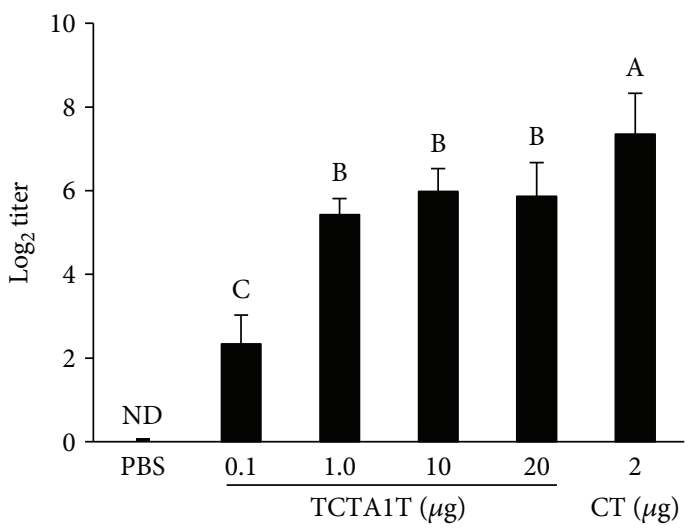

(d)

FIGURE 2: Intranasal TCTA1T enhances OVA-specific systemic and mucosal immune responses. ( $a$ and b) BALB/c mice were immunized i.n. with $20 \mu \mathrm{g}$ of OVA alone, plus $10 \mu \mathrm{g}$ of TCTA1T and TmCTA1T or $2 \mu \mathrm{g}$ of CT on days 0,14 , and 28 . Samples were collected on day 13 or 14 after the last immunization. The levels of OVA-specific IgG1 and IgG2a in sera (a) and IgA in mucosal external secretions (b) were determined by ELISA. ( $c$ and d) BALB/c mice were immunized three times at 2-week intervals by i.n. injection with $20 \mu \mathrm{g}$ of OVA alone, or plus $0.1,1.0,10$, and $20 \mu \mathrm{g}$ of TCTA1T, or $2 \mu \mathrm{g}$ of CT. The levels of OVA-specific IgG in sera (c) and IgA in saliva (d) were determined by ELISA. ND, not detectable. The results are expressed as mean $\pm \mathrm{SD}$ for the group $(n=5$ to 6$)$. The data are representative of three separate experiments. The different letters within the same samples are significantly different $(P<0.05)$.

were considerably lower than those detected in mice immunized with TCTA1T. Meanwhile, the levels of OVA-specific serum IgG1 and IgG2a titers elicited by CTA1 were 4 -fold lower than those induced by TCTA1T (data not shown). In addition, we observed that IgG1 was the predominant isotype in the sera of mice that had received OVA with TCTA1T, TmCTA1T, or CT (Figure 2(a)).

Various aspects of mucosal immunity serve critical functions in the defense against respiratory pathogens; one of which is the production and secretion of mucosal IgAs [3]. To examine whether adjuvantation of OVA with TCTA1T also enhances the mucosal IgA responses, OVA-specific mucosal IgA titers were examined in saliva, nasal wash, BAL, and lung tissues of the immunized mice. While i.n. delivery of OVA alone failed to induce OVA-specific IgAs, significant levels of OVA-specific sIgAs were observed in all external secretions of mice that received OVA immunization with TCTA1T or CT. Meanwhile, immunization with TmCTA1T elicited moderately higher levels of OVA-specific sIgAs in nasal wash, BAL, and lung tissues than those elicited by immunization with OVA alone (Figure 2(b)). Hence, these results indicate that adjuvantation of an Ag with TCTA1T enhances the Ag-specific mucosal sIgA secretion upon i.n. delivery and that ADP-ribosyltransferase activity may be associated with the immune-enhancing functionality of TCTA1T.

Further, in order to determine the optimal dose of TCTA1T to be used in mucosal immunizations, BALB/c mice were immunized i.n. three times with OVA mixed with $0.1,1.0,10$, or $20 \mu \mathrm{g}$ of TCTA1T. The levels of OVA-specific $\operatorname{IgG}$ and $\operatorname{IgA}$ in sera and saliva were increased in a dosedependent manner following immunization, and the observed dose-dependent increase in OVA-specific Ab titers peaked at $10 \mu \mathrm{g}$ dose for both serum IgG and salivary IgA (Figures 2(c) and 2(d)). Taken together, these results suggest that i.n. administration of TCTA1T as a mucosal adjuvant effectively enhances the systemic and mucosal $\mathrm{Ab}$ responses to the coadministered Ag.

3.4. TCTA1T Enhances In Vivo Ag-Specific Cytotoxic T Lymphocyte Response. Cytotoxic T lymphocyte (CTL) 
response in the mucosal tissues plays a crucial role in the clearance of viruses that infect mucosal epithelia [2], and coadministration of CT with a soluble protein Ag has been known to enhance Ag-specific CTL response [35]. To assess the CTL activity induced by TCTA1T, we performed in vivo CTL assay in the spleen and lung against the $\mathrm{OVA}_{257-264}$ epitope (SIINFEKL) which is recognized by $\mathrm{H}-$ $2 \mathrm{~Kb}$ MHC class I molecules. The in vivo CTL activity elicited by the TCTA1T was slightly lower than that by the CT but still much higher when compared to that by the TmCTA1T and OVA alone in the lung and spleen (Figure 3). Overall, these results indicate that mucosal immunization in the presence of TCTA1T effectively potentiates the induction of systemic and mucosal CTL response that is specific to the coadministered soluble Ag.

3.5. TCTA1T Adjuvant Enhances Protection against Lethal Infection with Influenza Virus. We have previously reported that mucosal vaccination of recombinant influenza virus M2 protein with CT offers better protection against lethal influenza virus challenge than parenteral vaccination [30]. In view of better protection offered by mucosal vaccination, we further explored the potential of using TCTA1T as the mucosal adjuvant for a M2 protein-based influenza vaccine. Coadministration of recombinant influenza M2 protein with TCTA1T or CT provided almost complete protection against lethal influenza virus challenge (survival rate $83.3 \%$ and $100 \%$, resp.), whereas none of the mice immunized with M2 protein with TmCTA1T or control groups (PBS or TCTA1T alone) survived after challenge with $10 \mathrm{LD}_{50}$ of influenza virus (Figure 4(a)). Furthermore, we observed a significant body weight loss in the mice immunized with M2 protein with TmCTA1T or control groups compared to mice that received M2 protein with TCTA1T or CT (Figure 4(b)). These results demonstrate that mucosal immunization of mice with influenza M2 protein in mixture with TCTA1T enhances the protective immunity against influenza virus challenge and provide evidential support for effectiveness of TCTA1T as a potential adjuvant for M2-based mucosal influenza vaccines.

3.6. TCTA1T Adjuvant Is Safe. It is well known that CT possesses a potent adjuvant activity. However, it is not licensed for human use because of its toxicity [6]. To assess the potential toxicity of TCTA1T, three different CT toxicity tests-footpad edema, the intestinal loop, and the cAMP secretion test-were performed with minor modifications. Treatment of mice with CT proved toxic in vivo as shown by the results of footpad edema (Figure 5(a)) and intestinal loop tests (Figure 5(b)), whereas no evident sign of toxicity was observed following TCTA1T treatment. In addition, treatment of BHK21 cells with TCTA1T induced a marginal secretion of cAMP in levels significantly lower than the cAMP secretion caused by CT treatment (Figure 5(c)). The ADP-ribosylating activity produced by TCTA1T treatment was approximately $15 \%$ in value of that produced by CT treatment, which is comparable in ratio to the ADPribosylating activity exhibited by CTA1-DD treatment as reported in a previous study [18]. Next, we further examined

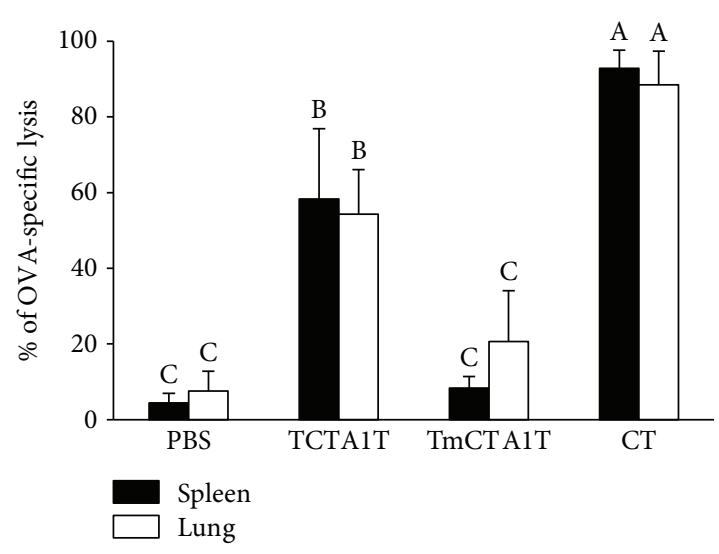

FIgURE 3: TCTA1T promotes OVA-specific CTL responses. C57BL/6 mice ( $n=3$ to 6 ) were immunized with $100 \mu \mathrm{g}$ of OVA alone, plus TCTA1T, TmCTA1T, or CT on days 0,14 , and 28. The immunized mice were injected i.v. with OVA peptide-pulsed and nonpulsed target cells. OVA-specific target cell lysis was determined in the spleen and lungs by flow cytometry. Data are expressed as mean \pm SD. Data are representative of three separate experiments. The different letters within the same samples are significantly different $(P<0.05)$.

the toxicity associated with i.n. administration of TCTA1T in the lung tissue of the mice. Administration with $5 \mu \mathrm{g}$ of CT resulted in a considerable increase in lung weight and caused significant body weight loss. However, no significant increase in the lung tissue weight or body weight loss was observed in the mice that received 10 or $50 \mu \mathrm{g}$ of soluble TCTA1T (Figures 6(a) and 6(b)). Taken together, these results underscore the lack of toxicity associated with TCTA1T in both in vitro and in vivo models advocating the safety of TCTA1T as a mucosal adjuvant.

3.7. TCTA1T Is Not Immunogenic. Since the presence of preexisting Abs to an adjuvant may inhibit immune response against codelivered Ags [23, 24], we evaluated the intrinsic immunogenicity of TCTA1T. Briefly, BALB/c mice were immunized three times i.n. or i.d. with $2 \mu \mathrm{g}$ of CT or $10 \mu \mathrm{g}$ of TCTA1T. Two weeks after the last immunization, the levels of CTA1- or CT-specific serum Ab were measured by ELISA. While CT also induced CT- or CTA1-specific serum IgGs following i.n. and i.d. administration, no detectable levels of CTA1 - or CT-specific serum IgGs were observed following TCTA1T-adjuvanted immunization via either routes (Figures 7(a) and 7(b)). These results suggest that TCTA1T is not intrinsically immunogenic, even after repeated administration, and should thus be considered as an attractive adjuvant candidate for enhancing immune responses to coadministered vaccine antigens.

\section{Discussion}

In this study, we demonstrate that a novel recombinant fusion polypeptide (TCTA1T), derived from CT by replacing the CTB subunit with HIV-1 Tat PTD, has potent adjuvanticity, being capable of enhancing systemic and mucosal Ab as well as CTL responses to intranasally (i.n.) coadministered 


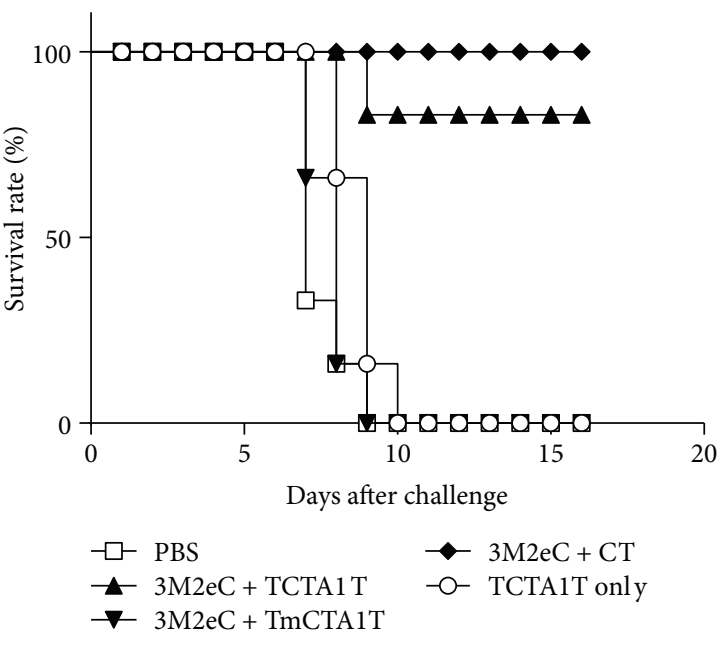

(a)

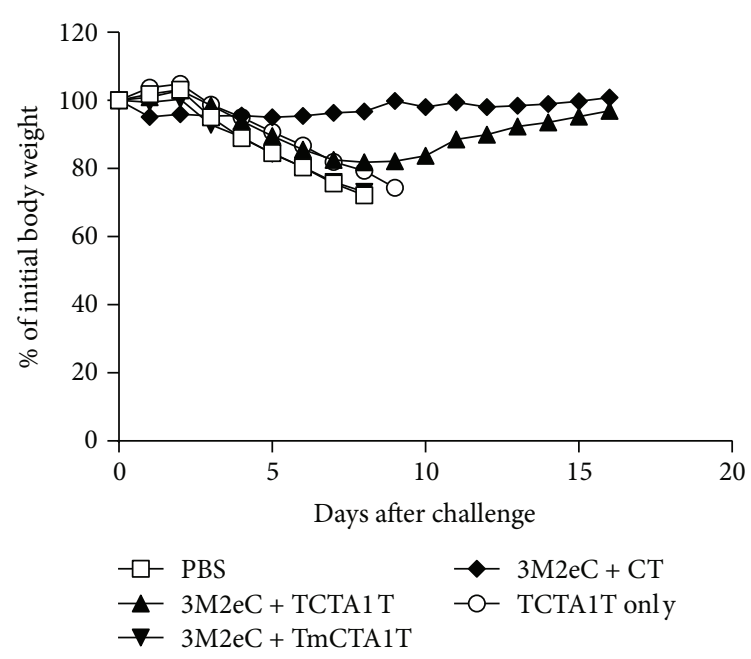

(b)

Figure 4: Protection against infection with $\mathrm{A} / \mathrm{PR} / 8$ virus. BALB/c mice $(n=5)$ were immunized two times at 2 -week intervals by i.n. administration with $10 \mu \mathrm{g}$ of influenza $3 \mathrm{M} 2 \mathrm{eC}$ protein with $10 \mu \mathrm{g}$ of TCTA1T and TmCTA1T, or $2 \mu \mathrm{g}$ of CT as an adjuvant. Control groups were immunized with PBS or TCTA1T alone. Mice were challenged i.n. with $10 \mathrm{LD}_{50}$ of A/PR/8 virus three weeks after the last immunization. Survival rate (a) and body weight (b) were monitored daily after the challenge. Data are representative of three separate experiments.

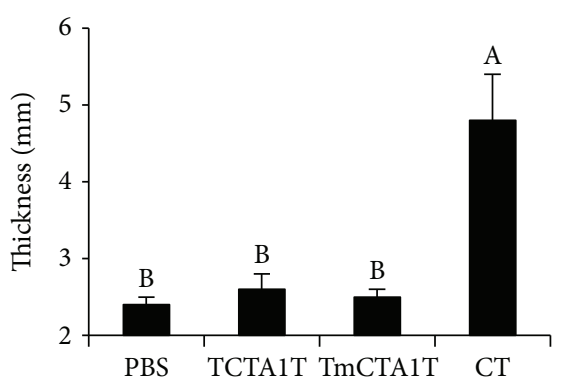

(a)

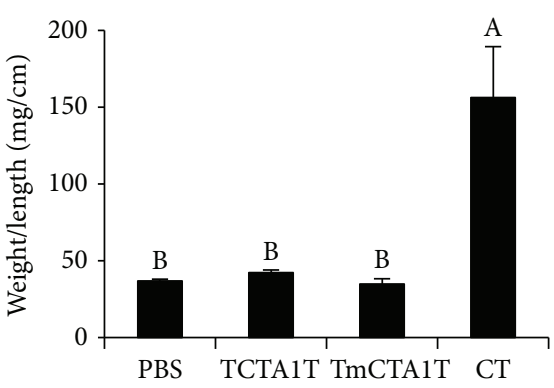

(b)

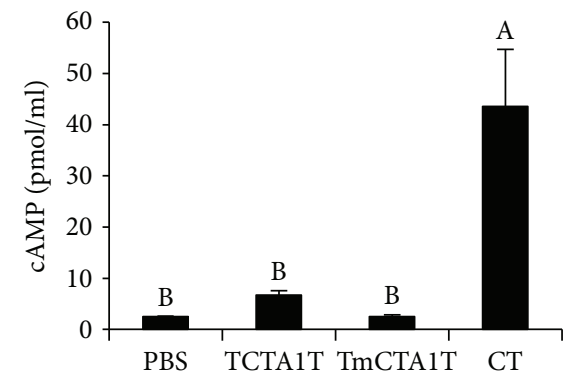

(c)

FIGURE 5: In vitro and in vivo toxicities of TCTA1T. (a) $20 \mu \mathrm{g}$ of TCTA1T and TmCTA1T or $1 \mu \mathrm{g}$ of CT in $10 \mu \mathrm{l}$ of PBS was injected into the hind paw. The thickness of the footpad was measured after 24 hrs. (b) Mice were anesthetized with ketamine, and abdomen was opened to make a loop in the small intestine. Then, $10 \mu \mathrm{g}$ of TCTA1T and TmCTA1T, or $2 \mu \mathrm{g}$ of CT, in $100 \mu \mathrm{l}$ of PBS were injected into the loop. The ratio of weight to length was determined after $6 \mathrm{hrs}$ and the data expressed as milligrams per centimeter (mg/cm) of fluid accumulation. (c) BHK21 cells were seeded at $1 \times 10^{6}$ cells/well in a 6-well plate. The cells were incubated with $10 \mu \mathrm{g}$ of TCTA1T and TmCTA1T, or $1 \mu \mathrm{g}$ of CT for $3 \mathrm{hrs}$. The concentration of cAMP in the supernatant was measured by ELISA according to the manufacturer's instructions. The results are expressed as mean \pm SD for the group $(n=3$ to 4$)$. Data are representative of two separate experiments. The different letters within the same samples are significantly different $(P<0.05)$.

antigen. In addition, we demonstrate that i.n. delivery of influenza M2 protein with TCTA1T provides near complete protection against lethal influenza virus challenge.
Furthermore, contrary to CT, TCTA1T lacked toxicity and self-immunogenicity, providing a rationale for the potential use of TCTA1T as a mucosal adjuvant due to its safety and 


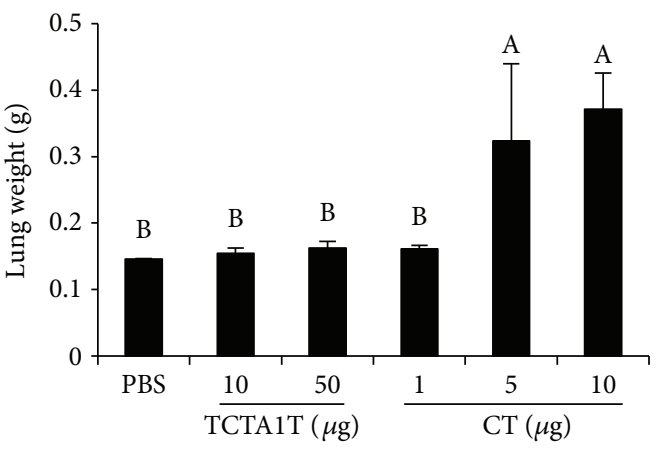

(a)

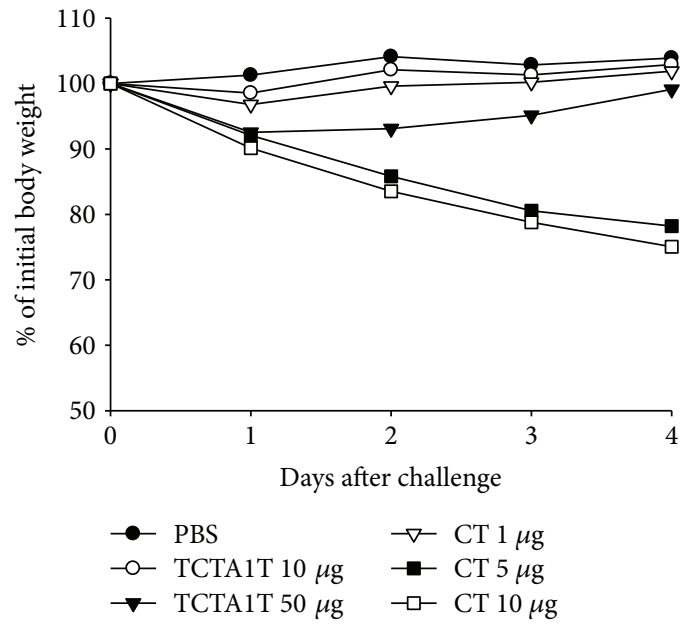

(b)

FIgURE 6: Comparison of toxicity effect between TCTA1T and CT in the lung tissue. The mice were administered i.n. with 10 or $50 \mu \mathrm{g}$ of TCTA1T or 1,5 , or $10 \mu \mathrm{g}$ of CT. PBS was used as a control. Lung tissues were removed from mice on day 4 after injection, and then (a) the weight of the lung was measured. (b) The mice were monitored daily for loss weight. The results are expressed as mean \pm SD for the group $(n=5)$. The different letters within the same samples are significantly different $(P<0.05)$.

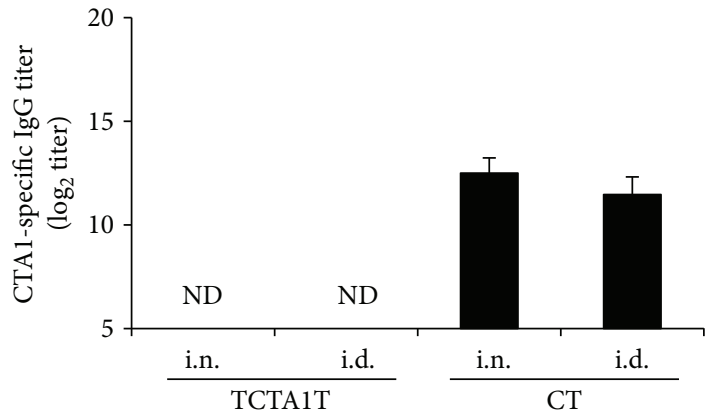

(a)

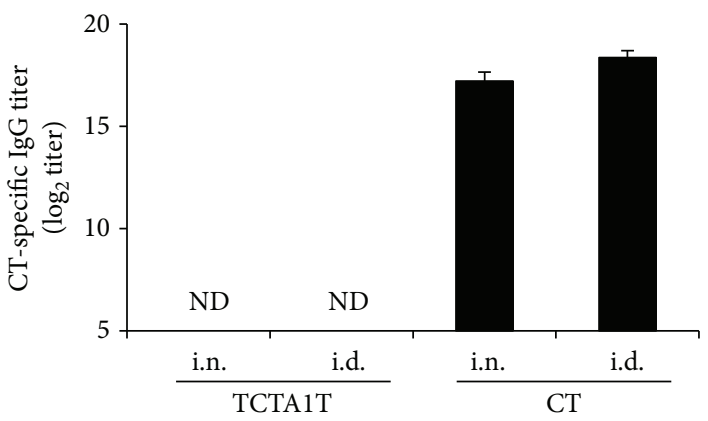

(b)

FIGURE 7: TCTA1T is not immunogenic. BALB/c mice were immunized three times with $2 \mu \mathrm{g}$ of CT or $10 \mu \mathrm{g}$ of TCTA1T by i.n. or i.d. routes. Sera were collected on day 14 after the last immunization. Levels of (a) CTA1- and (b) CT-specific IgG Abs in sera were determined by ELISA. The results are expressed as mean \pm SD for the group $(n=3)$. ND stands for not detectable.

ability to enhance both humoral and cellular immunities to the codelivered Ag.

CT is a well-known mucosal adjuvant in experimental animals but its toxicity precludes its use in humans [6]. In its native state, CTA1 subunit is internalized into the cell cytoplasm following binding of CTB subunits to cell surface GM1 ganglioside receptors, resulting in increased intracellular cAMP levels, disruption of ion channels, and hypersecretion of electrolytes and water leading to severe diarrhea [13, 14]. Our goal was to eliminate the toxicity of CT while retaining its adjuvanticity. To this end, we engineered a novel CTA1-based adjuvant capable of HIV-1 Tat protein PTDdependent cellular entry, bypassing the need for the presence of CTB for the cellular translocation of CTA1. Our rationale for fusing HIV-1 Tat PTD to CTA1 emanated from the previous studies describing the ability of HIV-1 Tat PTD to permeate across the cell membrane in a receptor-independent manner $[36,37]$ and to deliver PTD fusion proteins into living cells $[26,27]$. Accordingly, we have successfully shown in our study that using TCTA1T as mucosal adjuvant was effective in eliciting desired immune responses against the coadministered Ag. Also, given that TCTA1T lacks CTB domain, our finding indicates that CTB domain may be dispensable for the adjuvanticity of CT. This notion is also supported by the previous finding that CTA domain determines the adjuvanticity of CT [38].

However, the question of whether a direct correlation exists between the ADP-ribosyltransferase activity and the adjuvanticity of CT still remains controversial. Previous studies have demonstrated that two CT mutants, designated S61F and E112K, containing a point mutation within the ADP-ribosyltransferase active site of CTA1 domain retained their adjuvanticity without toxicity $[39,40]$, indicating that ADP-ribosyltransferase activity may not be required to establish the adjuvanticity of CT. Based on our study, however, while both TCTA1T and TmCTA1T were minimally or not toxic, TCTA1T, which possesses approximately $15 \%$ of the enzymatic activity of the intact CT, induced much higher mucosal and systemic Ab and CTL responses than those induced by TmCTA1T, in which 
ADP-ribosyltransferase functionality had been inactivated. In line with our findings, another study has reported that CTA1-DD possessing 10-20\% of ADP-ribosyltransferase activity of the CT holotoxin, but, not mCTA1 E112K-DD, completely lacking the ADP-ribosyltransferase activity, induced significant immune responses to codelivered Ag following i.n. administration [18]. Taken together, our results support the notion that ADP-ribosyltransferase activity within CTA1 is essential for retaining the adjuvanticity of CT.

Importantly, we also demonstrate that TCTA1T does not exhibit in vitro or in vivo toxicity as shown through various toxicity tests, and the absence of toxicity following TCTA1T treatment may be associated with the cellular transport and location of TCTA1T which may differ from that of CT. Given the disparity in mechanism for cellular entry, it is possible to consider that TCTA1T and CT are transported to different sites within cells upon entry, and such differential cellular localization may contribute to the establishment of their toxicity. It is also possible that the addition of extra amino acids to the N-terminus of CTA1 via Tat PTD fusion may have caused steric interference on ADP-ribosyltransferase catalytic site and reduced toxicity of TCTA1T. This is in accordance with the observation made in a previous study that an increasing peptide chain length at the N-terminus of CTA is inversely correlated to its toxicity [41]. However, mechanism through which the absence of toxicity associated with TCTA1T observed in our present study is to be further investigated.

Another important requirement for an ideal adjuvant is the absence of immunogenicity to itself [42]. Preexisting immunity to an adjuvant could potentially interfere with adjuvant activity by preventing its uptake by antigenpresenting. Preexisting immunity to CTB has been shown to have a negative effect on the induction of immune responses to protein Ags conjugated to CTB [23, 24]. Unfortunately, some bacteria toxin-derived mutants were shown to induce significant antitoxin immunity, although adjuvantreactive Abs did not appear to interfere with their adjuvanticity $[21,22]$. Nonetheless, our data indicate that TCTA1T was poorly if at all immunogenic per se, minimizing the concerns of a potential loss of adjuvanticity arising from preexisting antiadjuvant immunity.

\section{Conclusion}

In conclusion, our study demonstrates that recombinant TCTA1T is a potent and effective candidate mucosal adjuvant, being capable of enhancing both humoral and cellular immune responses to a coadministered antigen. Being minimally toxic and if at all immunogenic, TCTA1T possesses attractive properties to be considered as a safe and efficient mucosal adjuvant.

\section{Abbreviations}

$\begin{array}{ll}\text { Ab: } & \text { Antibody } \\ \text { Ag: } & \text { Antigen } \\ \text { BAL: } & \text { Bronchoalveolar lavage } \\ \text { cAMP: } & \text { Cyclic AMP }\end{array}$

$\begin{array}{ll}\text { CT: } & \text { Cholera toxin } \\ \text { CTA: } & \text { Cholera toxin A subunit } \\ \text { CTB: } & \text { Cholera toxin B subunit } \\ \text { CTL: } & \text { Cytotoxic T lymphocyte } \\ \text { HIV-1: } & \text { Human immunodeficiency virus type 1 } \\ \text { i.d.: } & \text { Intradermal } \\ \text { i.n.: } & \text { Intranasal } \\ \text { i.p.: } & \text { Intraperitoneal } \\ \text { i.v.: } & \text { Intravenous } \\ \text { LT: } & \text { Heat-labile toxin } \\ \text { GM1: } & \text { Monosialoganglioside } \\ \text { PTD: } & \text { Protein transduction domain } \\ \text { sIgA: } & \text { Secretory IgA } \\ \text { Tat: } & \text { Transcriptional activator } \\ \text { TCTA1T: } & \text { Attached protein of PTD at both N-terminus } \\ & \text { and C-terminus of CTA1 } \\ \text { TmCTA1T: } & \text { Mutant TCTA1T } \\ \text { TLR: } & \text { Toll-like receptor. }\end{array}$

\section{Disclosure}

Portions of this study have been presented in a poster form at Vaccines for Enteric Diseases (VED), the Royal College of Physicians of Edinburgh, UK, on July 2015.

\section{Conflicts of Interest}

The authors declare that there is no conflict of interest regarding the publication of this article.

\section{Authors' Contributions}

Byoung-Shik Shim and In Su Cheon contributed equally to this work.

\section{Acknowledgments}

This work was supported in part by grants from the Vaccine Translational Research Center of the Republic of Korea (Project no. HI13C0826), and the European Union Framework Program 7 (ADITEC project) to Cecil Czerkinsky is gratefully acknowledged.

\section{References}

[1] L. B. Lawson, E. B. Norton, and J. D. Clements, "Defending the mucosa: adjuvant and carrier formulations for mucosal immunity," Current Opinion in Immunology, vol. 23, no. 3, pp. 414-420, 2011.

[2] M. R. Neutra and P. A. Kozlowski, "Mucosal vaccines: the promise and the challenge," Nature Reviews Immunology, vol. 6, no. 2, pp. 148-158, 2006.

[3] N. Lycke and M. Bemark, "Mucosal adjuvants and long-term memory development with special focus on CTA1-DD and other ADP-ribosylating toxins," Mucosal Immunology, vol. 3, no. 6, pp. 556-566, 2010.

[4] J. Holmgren and C. Czerkinsky, "Mucosal immunity and vaccines," Nature Medicine, vol. 11, no. 4s, pp. S45-S53, 2005. 
[5] Y. Yuki and H. Kiyono, "Mucosal vaccines: novel advances in technology and delivery," Expert Review of Vaccines, vol. 8, no. 8, pp. 1083-1097, 2009.

[6] M. Pizza, M. Giuliani, M. Fontana et al., "Mucosal vaccines: non toxic derivatives of LT and CT as mucosal adjuvants," Vaccine, vol. 19, no. 17-19, pp. 2534-2541, 2001.

[7] R. L. Coffman, A. Sher, and R. A. Seder, "Vaccine adjuvants: putting innate immunity to work," Immunity, vol. 33, no. 4, pp. 492-503, 2010.

[8] M. Kubota, C. J. Miller, K. Imaoka et al., "Oral immunization with simian immunodeficiency virus p55gag and cholera toxin elicits both mucosal IgA and systemic IgG immune responses in nonhuman primates," The Journal of Immunology, vol. 158, no. 11, pp. 5321-5329, 1997.

[9] K. Imaoka, C. J. Miller, M. Kubota et al., "Nasal immunization of nonhuman primates with simian immunodeficiency virus p55gag and cholera toxin adjuvant induces Th1/Th2 help for virus-specific immune responses in reproductive tissues," The Journal of Immunology, vol. 161, no. 11, pp. 5952-5958, 1998.

[10] N. Cuburu, M. N. Kweon, J. H. Song et al., "Sublingual immunization induces broad-based systemic and mucosal immune responses in mice," Vaccine, vol. 25, no. 51, pp. 8598-8610, 2007.

[11] J. Sanchez and J. Holmgren, "Cholera toxin structure, gene regulation and pathophysiological and immunological aspects," Cellular and Molecular Life Sciences, vol. 65, no. 9, pp. 1347-1360, 2008.

[12] J. D. Clements, N. M. Hartzog, and F. L. Lyon, “Adjuvant activity of Escherichia coli heat-labile enterotoxin and effect on the induction of oral tolerance in mice to unrelated protein antigens," Vaccine, vol. 6, no. 3, pp. 269-277, 1988.

[13] B. D. Spangler, "Structure and function of cholera toxin and the related Escherichia coli heat-labile enterotoxin," Microbiology and Molecular Biology Reviews, vol. 56, pp. 622-647, 1992.

[14] M. M. Levine, J. B. Kaper, R. Black, and M. Clements, "New knowledge on pathogenesis of bacterial enteric infections as applied to vaccine development," Microbiology and Molecular Biology Reviews, vol. 47, pp. 510-550, 1983.

[15] M. M. Levine, R. Black, M. Clements et al., "Evaluation in humans of attenuated Vibrio cholerae El Tor Ogawa strain Texas Star-SR as a live oral vaccine," Infection and Immunity, vol. 43, no. 2, pp. 515-522, 1984.

[16] M. Field, "Intestinal ion transport and the pathophysiology of diarrhea," Journal of Clinical Investigation, vol. 111, no. 7, pp. 931-943, 2003.

[17] L. C. Agren, L. Ekman, B. Lowenadler, and N. Y. Lycke, "Genetically engineered nontoxic vaccine adjuvant that combines $\mathrm{B}$ cell targeting with immunomodulation by cholera toxin A1 subunit," Journal of Immunology, vol. 158, pp. 3936-3946, 1997.

[18] A. M. Eriksson, K. M. Schön, and N. Y. Lycke, "The cholera toxin-derived CTA1-DD vaccine adjuvant administered intranasally does not cause inflammation or accumulate in the nervous tissues," The Journal of Immunology, vol. 173, no. 5, pp. 3310-3319, 2004.

[19] J. A. Lapa, S. A. Sincock, M. Ananthakrishnan et al., "Randomized clinical trial assessing the safety and immunogenicity of oral microencapsulated enterotoxigenic Escherichia coli surface antigen 6 with or without heat-labile enterotoxin with mutation R192G," Clinical and Vaccine Immunology, vol. 15, no. 8, pp. 1222-1228, 2008.
[20] S. Peppoloni, P. Ruggiero, M. Contorni et al., "Mutants of the Escherichia coli heat-labile enterotoxin as safe and strong adjuvants for intranasal delivery of vaccines," Expert Review of Vaccines, vol. 2, no. 2, pp. 285-293, 2003.

[21] N. Lycke and K. Schon, "The B cell targeted adjuvant, CTA1DD, exhibits potent mucosal immunoenhancing activity despite pre-existing anti-toxin immunity," Vaccine, vol. 19, no. 17-19, pp. 2542-2548, 2001.

[22] M. Ugozzoli, G. Santos, J. Donnelly, and D. T. O’Hagan, "Potency of a genetically detoxified mucosal adjuvant derived from the heat-labile enterotoxin of Escherichia coli (LTK63) is not adversely affected by the presence of preexisting immunity to the adjuvant," The Journal of Infectious Diseases, vol. 183, no. 2, pp. 351-354, 2001.

[23] C. Bergquist, T. Lagergard, and J. Holmgren, “Anticarrier immunity suppresses the antibody response to polysaccharide antigens after intranasal immunization with the polysaccharide-protein conjugate," Infection and Immunity, vol. 65, p. 1579, 1997.

[24] W. HY and M. W. Russell, "Comparison of systemic and mucosal priming for mucosal immune responses to a bacterial protein antigen given with or coupled to cholera toxin (CT) B su," Vaccine, vol. 12, no. 3, pp. 215-222, 1994.

[25] E. L. Snyder and S. F. Dowdy, "Cell penetrating peptides in drug delivery," Pharmaceutical Research, vol. 21, no. 3, pp. 389-393, 2004.

[26] S. R. Schwarze, A. Ho, A. Vocero-Akbani, and S. F. Dowdy, "In vivo protein transduction: delivery of a biologically active protein into the mouse," Science, vol. 285, no. 5433, pp. 1569$1572,1999$.

[27] G. Cao, W. Pei, H. Ge et al., "In vivo delivery of a Bcl-xL fusion protein containing the TAT protein transduction domain protects against ischemic brain injury and neuronal apoptosis," The Journal of Neuroscience, vol. 22, no. 13, pp. 5423-5431, 2002.

[28] J. Park, J. Ryu, K. Kim et al., "Mutational analysis of a human immunodeficiency virus type 1 Tat protein transduction domain which is required for delivery of an exogenous protein into mammalian cells," Journal of General Virology, vol. 83, no. 5, pp. 1173-1181, 2002.

[29] J. Ryu, K. Han, J. Park, and S. Y. Choi, "Enhanced uptake of a heterologous protein with an HIV-1 Tat protein transduction domains (PTD) at both termini," Molecules and Cells, vol. 16, no. 3, pp. 385-391, 2003.

[30] B. S. Shim, Y. K. Choi, C. H. Yun et al., "Sublingual immunization with M2-based vaccine induces broad protective immunity against influenza," PLoS One, vol. 6, no. 11, article e27953, 2011.

[31] J. De Rycke, E. Oswald, and R. Boivin, "An in vivo assay for the detection of cytotoxic strains of Escherichia coli," Annals of Veterinary Research, vol. 20, no. 1, pp. 39-46, 1989.

[32] I. Ohishi, "Response of mouse intestinal loop to botulinum C2 toxin: enterotoxic activity induced by cooperation of nonlinked protein components," Infection and Immunity, vol. 40, p. $691,1983$.

[33] J. B. Lee, J. E. Jang, M. K. Song, and J. Chang, "Intranasal delivery of cholera toxin induces th17-dominated T-cell response to bystander antigens," PLoS One, vol. 4, no. 4, article e5190, 2009.

[34] M. R. Fontana, R. Manetti, V. Giannelli et al., "Construction of nontoxic derivatives of cholera toxin and characterization of 
the immunological response against the A subunit," Infection and Immunity, vol. 63, no. 6, pp. 2356-2360, 1995.

[35] J. C. Bowen, S. K. Nair, R. Reddy, and B. T. Rouse, "Cholera toxin acts as a potent adjuvant for the induction of cytotoxic T-lymphocyte responses with non-replicating antigens," Immunology, vol. 81, no. 3, pp. 338-342, 1994.

[36] M. Green and P. M. Loewenstein, “Autonomous functional domains of chemically synthesized human immunodeficiency virus tat trans-activator protein," Cell, vol. 55, no. 6, pp. 11791188, 1988.

[37] A. D. Frankel and C. O. Pabo, "Cellular uptake of the tat protein from human immunodeficiency virus," Cell, vol. 55, no. 6 , pp. 1189-1193, 1988.

[38] E. A. Campos, J. Namikoshi, S. Maeba, M. Yamamoto, M. Fukumoto, and H. Yamamoto, "Nasally administered cholera toxin A-subunit acts as a mucosal adjuvant," Journal of Oral Science, vol. 45, no. 1, pp. 25-31, 2003.

[39] S. Yamamoto, Y. Takeda, M. Yamamoto et al., "Mutants in the ADP-ribosyltransferase cleft of cholera toxin lack diarrheagenicity but retain adjuvanticity," The Journal of Experimental Medicine, vol. 185, no. 7, pp. 1203-1210, 1997.

[40] S. Yamamoto, H. Kiyono, M. Yamamoto et al., "A nontoxic mutant of cholera toxin elicits Th2-type responses for enhanced mucosal immunity," Proceedings of the National Academy of Sciences of the United States of America, vol. 94, no. 10 , pp. 5267-5272, 1997.

[41] J. Sánchez, G. Wallerström, M. Fredriksson, J. Ångström, and J. Holmgren, "Detoxification of cholera toxin without removal of its immunoadjuvanticity by the addition of (STa-related) peptides to the catalytic subunit. A potential new strategy to generate immunostimulants for vaccination," Journal of Biological Chemistry, vol. 277, no. 36, pp. 33369-33377, 2002.

[42] R. K. Gupta and G. R. Siber, "Adjuvants for human vaccines-current status, problems and future prospects*," Vaccine, vol. 13, no. 14, pp. 1263-1276, 1995. 


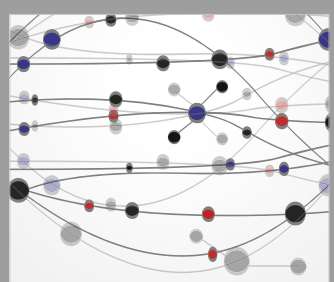

The Scientific World Journal
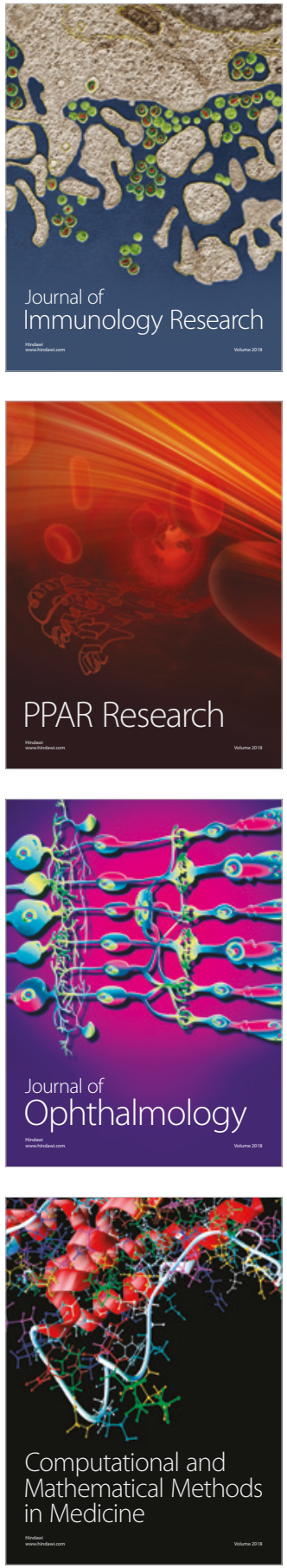

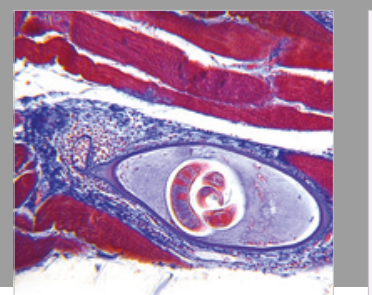

Gastroenterology Research and Practice

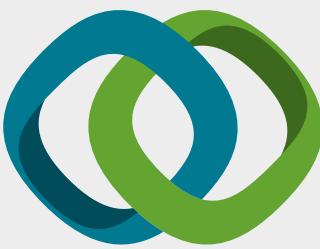

\section{Hindawi}

Submit your manuscripts at

www.hindawi.com
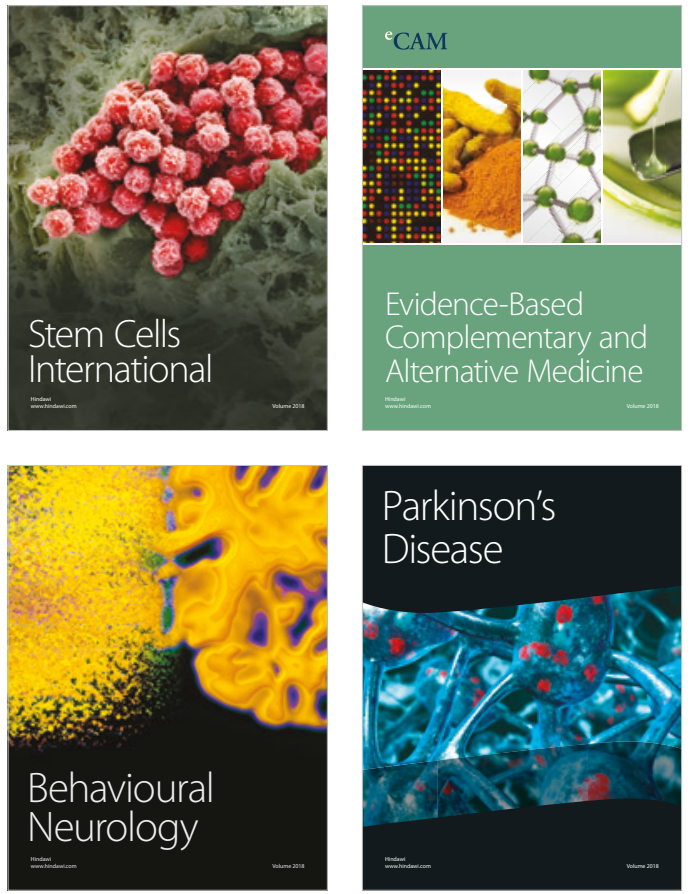

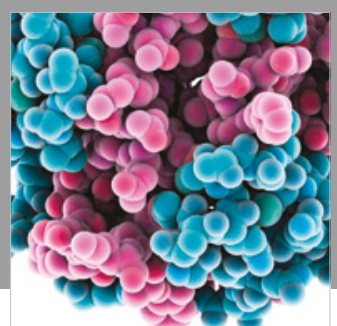

ournal of

Diabetes Research

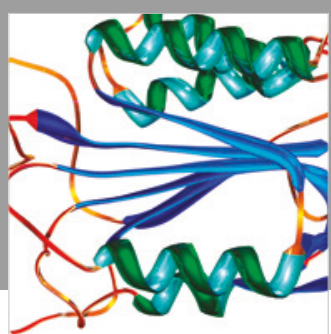

Disease Markers
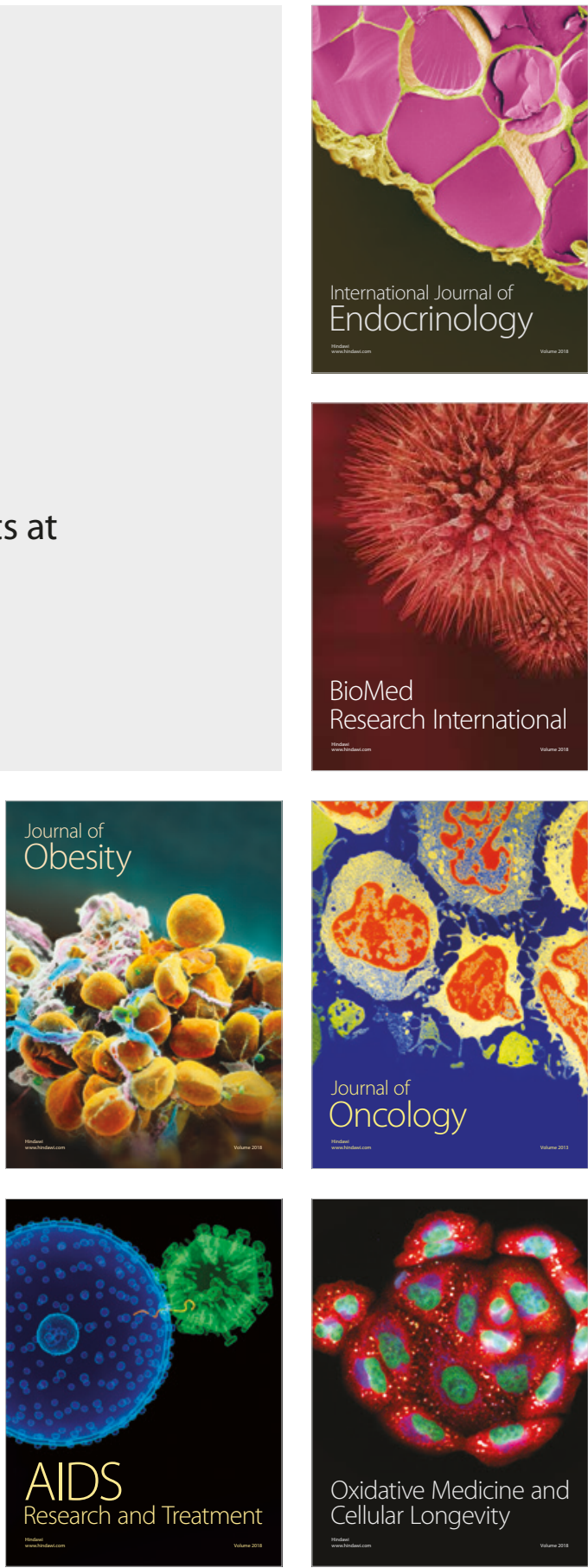